\title{
Change processes questionnaire for treatment of drug dependents based on transtheoretical model: Psychometric properties in Iran 2016
}

\author{
Reza Shahrabadi ${ }^{1}$, Gholamreza Garmaroudi², Davod Shojaeizadeh ${ }^{3}$, Mehdi Yaseri ${ }^{4}$
}

${ }^{1}$ Ph.D. Student in Health Education and Promotion, School of Public Health, Tehran University of Medical Sciences, Tehran, Iran

${ }^{2}$ Associate Professor, Department of Health Education and Promotion, School of Public Health, Tehran University of Medical Sciences, Tehran, Iran

${ }^{3}$ Professor, Department of Health Education and Promotion, School of Public Health, Tehran University of Medical Sciences, Tehran, Iran

${ }^{4}$ Assistant Professor, Department of Epidemiology and Biostatistics, School of Public Health, Tehran University of Medical Sciences, Tehran, Iran

\section{Type of article: Original}

\begin{abstract}
Background: Drug abuse is a serious subject that can lead to social, economic, cultural and health problems. The routine approaches in treatment of drug abuse are either medication or non-medication methods. Non-medication approach is focused on mental and social health. Non-drug treatment requires appropriate tools.

Objective: To determine the validity, reliability, and structure of the Processes of Change Questionnaire.

Methods: In this cross-sectional study, which was conducted in 2016, three hundred sixty-two drug dependents in Sabzevar Substance Abuse Treatment Centers (Iran) were enrolled in the study. Samples were selected through the multi-stage sampling method. They completed the 40-item Processes of Change Questionnaire (drug version). In this study, Backward-Forward method, confirmatory factor analysis (CFA), test-retest, Cronbach's alpha, content validity ratio (CVR) and content validity index (CVI) were used, using AMOS 5.0 and SPSS version 11.5 .

Results: Findings of the CFA showed the questionnaire has a good fit. The fit index of the CFA was calculated as 0.75. Cronbach's alpha was 0.93 for the whole questionnaire, and ranged from 0.51 to 0.88 for its different domains. Also, intraclass correlation coefficient (ICC) and content validity were satisfactory.

Conclusion: Based on the findings of this study, the processes of change 40-item questionnaire: drug version was a credible, reliable and valid tool to identify effective factors in the treatment drug abuse among the population of the Sabzevar, Iran.

Keywords: Transtheoretical Model, Substance-Related Disorders, Psychometrics
\end{abstract}

\section{Introduction}

Drug abuse is one of the most important psychosocial problems which may have harmful effects on the individual, family and culture, and is a serious barrier to human growth and development $(1,2)$. Now, drug abuse has become a public health problem worldwide (3). According to the world drug report of the United Nations office on drugs and crime in 2016, one in twenty adults, or a quarter of a billion people between the ages of 15 and 64 years, used at least one drug in 2014 (4). In Iran in 2012, 2.65 percent of people between the ages of 15 and 64 years used drugs. Also, according to the study of Zardosht et al. in 2010 (5), 35 percent of patients who were admitted to emergency in the city of Sabzevar, had experienced drug abuse. Therefore, treatment of drug dependents is a priority. The two methods of treatment for this health problem include medication and non-medication treatment patterns (6). In medical treatment, methadone or buprenorphine maintenance treatment are usually used (7). In non-medication

\section{Corresponding author:}

Associate Professor Dr. Gholamreza Garmaroudi, Department of Health Education and Promotion, School of Public Health, Tehran University of Medical Sciences, Tehran, Iran. Tel: +98.2188989128, Email: garmaroudi@tums.ac.ir Received: November 10, 2016, Accepted: April 09, 2017, Published: July 2017 iThenticate screening: March 24, 2017, English editing: June 12, 2017, Quality control: July 02, 2017

(C) 2017 The Authors. This is an open access article under the terms of the Creative Commons Attribution-NonCommercialNoDerivs License, which permits use and distribution in any medium, provided the original work is properly cited, the use is non-commercial and no modifications or adaptations are made. 
treatment, there are a variety of patterns, including individual, group, family and self-help treatments (8). Patterns of non-medication treatments include individual, group, family, self-help therapies (9). The main objectives of this type of treatment are to raise awareness and understand themselves and their surroundings (10). Therefore, the environment and knowledge are effective factors in drug abuse treatment (11) and on the environment; behavioral therapy should be considered (12). Behavioral therapy can be used with various techniques such as modeling, adaptability, relaxation training, rehearsal, contingency management, cue exposure, aversion and perceived susceptibility (13). Also with knowledge, cognitive therapy should be considered (14) it is formed with raising awareness and desirable attitudes (15). The results of several studies in Iran $(16,17)$ show that non-medication treatment of drug dependents is effective. The use of models and tools for non-medication treatment is functional (18). Also, it is necessary to apply models and tools in educational programs because the intervention will be purposeful and implemented more accurately if it is based on model principles and values (19). In non-medication treatment, it is used from different models. One of these is a transtheoretical model (TTM) (19). This model is used from Bandura, Bergin and Garfield, Freud, Rogers and Skinner views (19). The model was designed in 1983, initially based on the behavior of drug abuse. Over time, numerous surveys were employed, including smoking cessation, fruit and vegetable consumption, use of contraceptives, physical activity, breast cancer screening, prevention of skin cancer, alcohol consumption, weight control and prevention of AIDS (18-22). This model was revised by Prochaska in 1992 and 1997. It considers step by step treatment and social factors, so is widely applied in the treatment of drug abuse (19-21). The model consists of four structures: a) Stages of Change b) Self-Efficacy / temptation c) Decisional Balance and d) Processes of change (19). Among these structures, the process of change structure has 10 components. The structure is divided into two sections a) Behavioral process including Counter Conditioning, Stimulus Control, Self-Liberation, Reinforcement Management and Helping Relationship and b) Experimental process, including Consciousness Raising, Dramatic Relief, Self-Re-Evaluation, Environmental Reevaluation and Social Liberation (19). For review, the structure, Processes of Change Questionnaire (Drug Version) was designed by Prochaska for consumers of alcohol and drugs (22). This questionnaire is designed into two, from short (20 items) (23) and long (40 items) (23). This questionnaire (40 items) has been used in Mexico for American women so that appropriate validity and high reliability have been reported (24). Because of necessary interventions for drug dependence treatment in Iran (25) and that the interventions to change must be based on a model (19), it is highly important to devise a proper tool with proven validity and reliability that can be applied to the Iranian population. The present study aimed to determine the validity and reliability of the Processes of Change Questionnaire (Drug Version-40 items).

\section{Material and Methods}

\subsection{Research design and sampling}

This methodological research (Cross-sectional) was performed in 2016 on 362 drug dependents in Sabzevar Substance Abuse Treatment Centers, Iran. In this study, for generalization of confirmatory factor analysis (CFA) results must for any questions be between 5 to 10 people of the target group who complete the questionnaire $(26,27)$. Therefore, in this study, 400 samples were considered for 40 questions that finally, 362 drug dependents completed the questionnaire. The number of drug abuse treatment centers in Sabzevar were 32 and each center had between 50 to 100 drug dependents. In this study, multi-stage sampling (stratified- cluster in two stages) was used. First Sabzevar was divided into four geographical regions as class (stratified) and Substance Abuse Treatment Centers in each region as clusters were considered. Then in each region, based on the number of covered drug dependents, required numbers of clusters (treatment centers) were selected randomly. Finally, in each cluster based on the list of drug dependents, the numbers of required samples were selected randomly.

\subsection{Selection criteria}

Inclusion criteria were, having health records in the Substance Abuse Treatment Center and lack of mental disorders such as schizophrenia. An exclusion criterion was unwillingness of drug dependents to participate in the research (at any time of the research).

\subsection{Instrument, data collection and analyses}

Participants completed the processes of change 40-item questionnaire: drug version (23) which is used for drug abuse behavior. The questionnaire has two domains and each domain has five structures, including a) Behavioral process, including Counter Conditioning, Stimulus Control, Self-Liberation, Reinforcement Management and Helping Relationship and b) Experimental process, including Consciousness Raising, Dramatic Relief, Self-ReEvaluation, Environmental Re-evaluation and Social Liberation (22). This questionnaire was designed based on a 5point Likert scale (Never=1, Seldom=2, Occasionally $=3$, Frequently=4 and Repeatedly=5) (23). In this study, 
Backward-Forward method was used. Before performing the study, permission was granted by DiClemente (22) to apply this questionnaire by e-mail. First, the questionnaire was translated from English into Persian by a panel of health education experts and an English language translator. Its items were then revised according to the cultural norms of Iran and presented in the final version in the format of comprehensible items. Then, the items in Persian were translated into English by three translators. An English file was sent to the author of the questionnaire, but did not receive a response, unfortunately. Finally, the translation of English was compared with the original questionnaire by two translators of English. No difference was found between the two English translations. Face validity was determined by asking the points of views of experts and a sample of the target group. Ten experts in health education and promotion and 20 drug dependents who were randomly selected from the target group presented their views about fluency and understandability of the items. In this study, to assess the content validity of the questionnaire, content validity ratio (CVR) and content validity index (CVI) were determined. Content validation refers to a process that aims to provide assurance that a questionnaire measures the content area it is expected to measure (28). Ten experts were invited to complete a questionnaire for rating items into one of three categories (for CVR): "essential", "useful, but not essential" or "not necessary" (27). Then the questionnaire's CVR was assessed; according to the Lawshe (29) table if the item score was over 0.62, the item was considered as an appropriate and necessary one. Also, categories (for CVI): "relevance", "clarity", and "simplicity" examined the questions of the questionnaire based on the four? point scale (30).Items with the score of over 0.75 were retained as appropriate ones (30). Factorial validity of the Persian version of the Processes of Change Questionnaire was assessed using CFA. With CFA, factors were assessed with regard to the number of factors, number of questions and the pattern of questions for each factor (27). The minimum sample size required for the CFA was 5 per item (27). The questionnaire consists of 40 items; thus, the minimum sample size required was 200 . In this study, the number of samples was 362. This means that 9 samples were collected for each question. The CFA was conducted to examine the questionnaire constructs using Amos software. Several indexes are usually used in order to assess the adequacy of model fit (27). In this study, to assess the fit of the proposed questionnaire, the relative Chi-square, the goodness of fit index (GFI), adjusted goodness of fit index (AGFI), comparative fit index (CFI) and the root mean square error of approximation (RMSEA) were used. Index values are different: Acceptable model fits are indicated by relative Chi-square value smaller than 5. GFI and AGFI values vary between 0 and 1 with values greater than 0.9 indicating the model's goodness of fit. The CFI index also varies between 0 and 1 , with values closer to 1 making the model more appropriate and values in excess of 0.9 indicating the model's good fit. RMSEA values lower than 0.05 indicate a good fit; values about 0.08 indicate a moderate fit and values higher than 0.1 indicate the model's poor fit $(27,31,32)$. Reliability of the questionnaire for the whole, and then for each domain, was measured by TestRetest using the intraclass correlation coefficient (ICC) with associated $95 \%$ confidence interval $(95 \% \mathrm{CI})$ and Cronbach's alpha. Participants filled the questionnaires twice at an interval of two weeks. The ICC values were considered excellent if $\geq 0.81$, good from 0.61 to 0.80 , moderate from 0.41 to 0.60 , fair from 0.21 to 0.40 and poor if $\leq 0.20$ (33). Data were analyzed by AMOS 5.0 and SPSS version 11.5.

\section{Results}

In this study, 362 drug dependents were entered. The mean age of participants was $35.0 \pm 8.3$ years, ranging from 18 to 76. The characteristics of the study sample are shown in Table 1. In this study, CVR for each of the items was between 0.62 and 0.85 . Also, CVI for each of the items was higher than 0.80 .

Table 1. Demographic characteristics of the study sample $(\mathrm{n}=362)$

\begin{tabular}{|l|l|l|l|}
\hline Variables & $\mathrm{n}$ & $\%$ \\
\hline Gender & Man & 306 & 84.5 \\
\cline { 2 - 4 } & Woman & 56 & 15.5 \\
\hline \multirow{3}{*}{ Age (year) } & $<20$ & 5 & 1.4 \\
\cline { 2 - 4 } & $20-30$ & 104 & 28.7 \\
\cline { 2 - 4 } & $31-45$ & 219 & 60.5 \\
\cline { 2 - 4 } & $>46$ & 34 & 9.4 \\
\hline Marital status & Single & 126 & 34.9 \\
\cline { 2 - 4 } & Married & 236 & 65.1 \\
\hline Education (year) & $<12$ & 313 & 86.5 \\
\cline { 2 - 4 } & 12 & 25 & 6.9 \\
\cline { 2 - 4 } & $>12$ & 24 & 6.6 \\
\hline
\end{tabular}


The CFA was performed and the following fit indices were found: the goodness of fit index (GFI) $=0.75$; the adjusted goodness of fit index $(\mathrm{AGFI})=0.72$; the comparative fit index $(\mathrm{CFI})=0.74$; the root mean square error of approximation $($ RMSEA) $=0.071$ and the relative Chi-square $=2.72, p<0.001$. Since a remarkable improvement on fit indexes was not observed, no modifications were made. Thus, the model was accepted in its current form. The results are presented in Figure 1. Cronbach's alpha was applied separately for all twelve factors ranged between 0.51 and 0.88 , which are accepted value. In addition, the reliability of the instrument as measured by ICC was satisfactory. The results are given in Table 2 .

Table 2. The internal consistency and stability of the questionnaire as measured by Cronbach's alphas and intraclass correlation coefficient (ICC)

\begin{tabular}{|l|l|l|l|l|l|}
\hline Variable & Cronbach alpha & ICC & Number of items & \multicolumn{2}{|l|}{$95 \%$ CI } \\
\cline { 5 - 7 } & & & & Lower & Upper \\
\hline Experimental process & $\mathbf{0 . 8 7}$ & $\mathbf{0 . 9 1 6}$ & $\mathbf{2 0}$ & $\mathbf{0 . 8 3}$ & $\mathbf{0 . 9 6}$ \\
\hline Consciousness Raising & 0.65 & 0.880 & 4 & 0.76 & 0.94 \\
\hline Dramatic Relief & 0.59 & 0.642 & 4 & 0.37 & 0.81 \\
\hline Environmental Re-evaluation & 0.51 & 0.914 & 4 & 0.83 & 0.96 \\
\hline Self-Re-Evaluation & 0.70 & 0.796 & 4 & 0.61 & 0.90 \\
\hline Social Liberation & 0.61 & 0.757 & 4 & 0.63 & 0.86 \\
\hline Behavioral process & $\mathbf{0 . 8 8}$ & $\mathbf{0 . 9 2 4}$ & $\mathbf{2 0}$ & $\mathbf{0 . 8 5}$ & $\mathbf{0 . 9 6}$ \\
\hline Reinforcement Management & 0.62 & 0.930 & 4 & 0.86 & 0.97 \\
\hline Counter Conditioning & 0.58 & 0.691 & 4 & 0.45 & 0.84 \\
\hline Helping Relationship & 0.65 & 0.851 & 4 & 0.71 & 0.93 \\
\hline Self-Liberation & 0.69 & 0.807 & 4 & 0.63 & 0.90 \\
\hline Stimulus Control & 0.62 & 0.825 & 4 & 0.67 & 0.91 \\
\hline Total & $\mathbf{0 . 9 3}$ & $\mathbf{0 . 9 3 4}$ & $\mathbf{4 0}$ & $\mathbf{0 . 8 7}$ & $\mathbf{0 . 9 7}$ \\
\hline
\end{tabular}

Note: Figures in bold are calculated for Experimental process, Behavioral process and for all items.

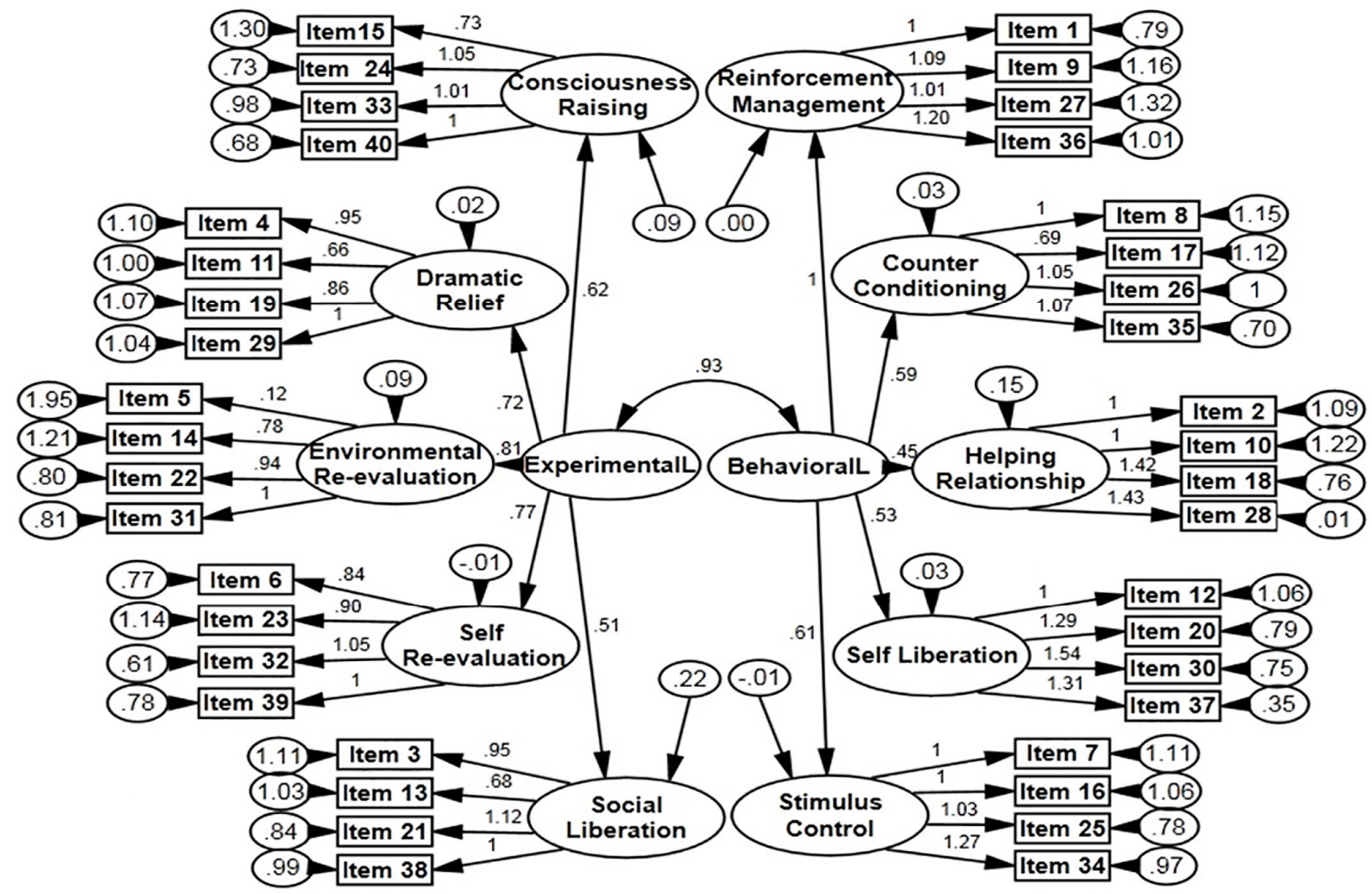

Figure1. The results obtained from the confirmatory factor analysis (items are observed variables, and subscales are latent variables). 


\section{Discussion}

This study assessed psychometric properties with application of the transtheoretical model for the translated Iranian version of the Processes of Change Questionnaire (Drug Version) for drug abuse behaviors. Results of CFA showed the subscales of the questionnaire are approved. These ten subscales are one of the important structures in TTM that is called processes of change. The process of change is a key construct of the TTM (19) that is used to make progress in the desired behavior in health interventions. In fact, this model suggests that the process of change should be considered when designing a tailored intervention for drug abuse treatment so that in many studies (3436), health behaviors are used from TTM. In this study, to assure instrument reliability, two statistical tests were performed: Cronbach's alpha coefficients and Test-Retest reliability showed that the indicated tool has good internal consistency. The results of this study were consistent with the study of Sarbandi et al. (37) and Gaume et al. (38). The study of Sarbandi et al. (37) assessed the transtheoretical model questionnaire for smoking cessation in the Iranian version. ICC of processes of change obtained 0.70 (37) that showed good reliability, and our study obtained 0.93 that showed excellent reliability. The findings indicated that the translated questionnaire has an acceptable fit (According to indicators GFI, AGFI, CFI, RMSEA, x2/df). Many studies have assessed psychometric properties of TTM-based questionnaires that relate to health behaviors, especially drug abuse, that are in agreement with our findings for approval of the questionnaire (39-41). This result was similar to findings by Massey et al. (42) for the processes of change in a Psychological Skills Training Questionnaire. In general, the result showed that it was a valid instrument for measuring drug abuse behavior change and treatment among Iranians. Theory-based tools are an important factor for implementing, monitoring and evaluating health education and promotion interventions. According to this, the findings of this study can be helpful for non-medication treatment in all fields of education and research. Prochaska et al. (22) assessed that the psychometric properties of processes of change 40-item questionnaire used for cessation of smoking; had a good fit according to the CFA (GFI $>0.7$ ) as in our study. In Prochaska's study (22), internal consistency was established with alpha coefficients ranging from 0.69 to 0.92 which was slightly in line with the results of this study (between 0.51 and 0.88 ). Limitations of this study were being a selfreport questionnaire and lack of cooperation by some of the drug dependents in completing the questionnaire.

\section{Conclusions}

This study, by translating and psychometric properties is one of the important tools for the assessment of drug abuse behaviors in health education and promotion of drug dependents, and provides the context for the widespread application of the tool. According to the results of this study, the 40-item Process of Change Questionnaire (drug version) was confirmed to be an efficient tool to use in non-medication interventions for drug abuse treatment and assessment of drug abuse behaviors promotion in Iran; researchers and therapists can use it as a valid and reliable tool.

\section{Acknowledgments:}

This paper was devised from the first author's PhD thesis at the School of Public Health, Tehran University of Medical Sciences. The institutional ethics committee approved the ethics of the study (Ref: IR.TUMS.REC.1394.1406). The authors thank the School of Public Health, Tehran University of Medical Sciences for its support.

\section{Conflict of Interest:}

There is no conflict of interest to be declared.

\section{Authors' contributions:}

All authors contributed to this project and article equally. All authors read and approved the final manuscript.

\section{References:}

1) Degenhardt L, Hall W. Extent of illicit drug use and dependence, and their contribution to the global burden of disease. Lancet. 2012; 379(9810): 55-70. doi: 10.1016/S0140-6736(11)61138-0. PMID: 22225671 .

2) Rogers JD, Ramaswamy M, Cheng CI, Richter K, Kelly PJ. Perceptions of neighborhood social environment and drug dependence among incarcerated women and men: a cross-sectional analysis. Subst Abuse Treat Prev Policy. 2012; 7: 39. doi: 10.1186/1747-597X-7-39. PMID: 22963546, PMCID: PMC3511875. 
3) Degenhardt L, Whiteford HA, Ferrari AJ, Baxter AJ, Charlson FJ, Hall WD, et al. Global burden of disease attributable to illicit drug use and dependence: findings from the Global Burden of Disease Study 2010. Lancet. 2013; 382(9904): 1564-74. doi: 10.1016/S0140-6736(13)61530-5. PMID: 23993281.

4) World Drug Report. United Nations Office On Drugs and Crime. Vienna; New York; 2016. Available From: https://www.unodc.org/doc/wdr2016/WORLD_DRUG_REPORT_2016_web.pdf.

5) Zardosht R, Hashemian M, Akbary A. Assessment of substance abuse among victims and its relation to incident type in patients referring to emergencies of Sabzevar Vasei and Emdadi hospitals. Studies, Research and Education Centre of Headquarters for Combating Drugs. 2010. Available From: http://dchq.ir/images/motalehat/list-r.pdf.

6) O'Grady CL, Surratt HL, Kurtz, SP, Levi-Minzi MA. Nonmedical prescription drug users in private vs. public substance abuse treatment: a cross sectional comparison of demographic and HIV risk behavior profiles. Subst Abuse Treat Prev Policy. 2014; 9: 9. doi: 10.1186/1747-597x-9-9. PMID: 24495784, PMCID: PMC3915073.

7) Marmorstein NR, Iacono WG, McGue M. Alcohol and illicit drug dependence among parents: associations with offspring externalizing disorders. Psychol Med. 2009; 39(1): 149-55. doi: 10.1017/S0033291708003085. PMID: 18410699, PMCID: PMC2680685.

8) Armitage CJ. Can variables from the transtheoretical model predict dietary change? J Behav Med. 2010; 33(4): 264-73. doi: 10.1007/s10865-010-9261-0. PMID: 20407921.

9) Marcus DA, Atul Deodhar. Non-medication Treatments. Fibromyalgia. Springer New York: 2011; 159-74.

10) Weissman MM. Recent non-medication trials of interpersonal psychotherapy for depression. Int $J$ Neuropsychopharmacol. 2007; 10(1): 117-22. doi: 10.1017/S1461145706006936. PMID: 16787556.

11) Donohue B, Azrin NH, Bradshaw K, Van Hasselt VB, Cross CL, Urgelles J, et al. A controlled evaluation of family behavior therapy in concurrent child neglect and drug abuse. J Consult Clin Psychol. 2014; 82(4): 706-20. doi: 10.1037/a0036920. PMID: 24841866, PMCID: PMC4329246.

12) Riper H, Andersson G, Hunter SB, Wit J, Berking M, Cuijpers P. Treatment of comorbid alcohol use disorders and depression with cognitive - behavioural therapy and motivational interviewing: A meta analysis. Addiction. 2014; 109(3): 394-406. doi: 10.1111/add.12441. PMID: 24304463, PMCID: PMC4227588.

13) Massey WV. Behavior Change in Applied Sport Psychology: The Use of Processes of Change in Psychological Training for Athletes. Doctoral dissertation. University of Wisconsin Milwaukee. 2013.

14) Sofuoglu M, DeVito EE, Waters AJ, Carroll KM. Cognitive enhancement as a treatment for drug addictions. Neuropharmacology. 2013; 64: 452-63. doi: 10.1016/j.neuropharm.2012.06.021. PMID: 22735770, PMCID: PMC3445733.

15) Moshki M, Hassanzade T, Taymoori P. Effect of life skills training on drug abuse preventive behaviors among university students. Int J Prev Med. 2014; 5(5): 577-83. PMID: 24932389, PMCID: PMC4050678.

16) Ghorbani M. A study with special emphasis on applying motivational interviewing as a clinical approach to change addictive behavior of drug abusers in iran. Journal of research on addiction. 2002; 1(1):

17) Dabaghi P, Asgharnezhad AA, Atefnia MK, Bolhari J. Effectiveness of mindfulness-based relapse prevention in opioid dependence treatment \&mental health. Journal of research on addiction. 2008; 2(7): 29-44.

18) DiClemente CC. Addiction and change: How addictions develop and addicted people recover. Guilford Press; 2006.

19) Glanz K, Barbara K, Rimer K. Health Behavior And Health Education Theory, Research, and Practice. 4th ed. Published by Jossey-Bass: 2008; 97-117.

20) Ajzen I. Attitudes; Personality and Behavior. 2th Ed. Mcgraw-Hill: open University press; 2005; 914.

21) Prochaska JO, Velicer WF. The Transtheoretical Model of Health Behavior Change. American journal of health promotion. 1997; 12(1): 38-48. doi: 10.4278/0890-1171-12.1.38.

22) Prochaska JO, Velicer WF, DiClemente CC, Fava J. Measuring processes of change: applications to the cessation of smoking. J Consult Clin Psychol. 1988; 56(4): 520-8. doi: 10.1037/0022-006X.56.4.520. PMID: 3198809.

23) Processes of Change Questionnaire Drug Version: Form AB. The University of Maryland, Baltimore County. 2016. Available From: http://habitslab.umbc.edu/processes-of-change-questionnaire/.

24) Keller CS, McGowan N. Examination of the processes of change, decisional balance, self-efficacy for smoking and the stages of change in Mexican American women. Southern Online Journal of Nursing Research. 2001; 4(2): 1-31. 
25) Moeini B, Hazavehei MM, Shahrabadi R, Faradmal J, Dashti S. Role of stress in treatment readiness of drug dependence based on Health Belief Model. koomesh. 2015; 16(2): 185-92.

26) Heidarnia MA, Riazi Isfahani S, Abadi A, Mohseni M. Cross cultural adaptation and assessing validity and reliability of SERVQUAL questionnaire in hospital service quality. Research in Medicine. 2014; 38(2): 98105 .

27) Brown TA. Confirmatory factor analysis for applied research. New York: The Guilford Press; 2006.

28) Cook DA, Beckman TJ. Current concepts in validity and reliability for psychometric instruments: theory and application. Am J Med. 2006; 119(2): 166.e7-16. doi: 10.1016/j.amjmed.2005.10.036. PMID: 16443422 .

29) Lawshe CH. A quantitative approach to content validity1. Personnel psychology. 1975; 28(4): 563-75. doi: 10.1111/j.1744-6570.1975.tb01393.x.

30) Polit DF, Beck CT. The content validity index: are you sure you know what's being reported? Critique and recommendations. Res Nurs Health. 2006; 29(5): 489-97. doi: 10.1002/nur.20147. PMID: 16977646.

31) Kline RB. Principles and practice of structural equation modeling. 2nd ed. New York: The Guilford Press; 2005.

32) Hooper D, Coughlan J, Mullen M. Structural Equation Modelling: Guidelines for Determining Model Fit. Electronic Journal of Business Research Methods. 2008; 6(1): 53-60.

33) Streiner D, Norma G. Reliability. Health Measurement Scales: A practical guide to their development and use. New York (NY): Oxford University Press; 1995.

34) Saravani MR, Kajbaf MB, Amiri S, Abadi MR, Kianpour M. A comparison of the effects of motivational interviewing, group therapy based on change stages (transtheoretical model) and combination model on psychological symptoms among male substance abusers after deintoxication. IJCRB. 2012; 4(5): 25-33.

35) Kennedy KS. Motivation in substance abuse treatment: Assessing the relationship between the transtheoretical model of change, self-determination theory, and their impact upon treatment outcomes. Doctoral dissertation. The Ohio State University. 2005.

36) Gokbayrak NS, Paiva AL, Blissmer BJ, Prochaska JO. Predictors of relapse among smokers: transtheoretical effort variables, demographics, and smoking severity. Addict Behav. 2015; 42: 176-9. doi: 10.1016/j.addbeh.2014.11.022. PMID: 25481450, PMCID: PMC4272892.

37) Sarbandi F, Niknami S, Hidarnia A, Hajizadeh E, Montazeri A. The transtheoretical model (TTM) questionnaire for smoking cessation: psychometric properties of the Iranian version. BMC public health. 2013; 13: 1186. doi: 10.1186/1471-2458-13-1186. PMID: 24341503, PMCID: PMC3878568.

38) Gaume J, Bertholet N, Daeppen JB, Gmel G. The Change Questionnaire predicts change in hazardous tobacco and alcohol use. Addict Behav. 2013; 38(11): 2718-23. doi: 10.1016/j.addbeh.2013.07.004. PMID: 23934002.

39) Nidecker M, DiClemente CC, Bennett ME, Bellack AS. Application of the Transtheoretical Model of change: psychometric properties of leading measures in patients with co-occurring drug abuse and severe mental illness. Addict Behav. 2008; 33(8): 1021-30. doi: 10.1016/j.addbeh.2008.03.012. PMID: 18485611, PMCID: PMC2583262.

40) Guo B, Fielding A, Sutton S, Aveyard P. Psychometric properties of the processes of change scale for smoking cessation in UK adolescents. Int J Behav Med. 2011; 18(1): 71-8. doi: 10.1007/s12529-010-9085x. PMID: 20358321.

41) Kammerman BC. Internal consistency of the transtheoretical model's evaluation tools in a sample of college-age smokers. Master dissertation. University of Houston. 1999.

42) Massey WV, Meyer BB, Mullen SP. Initial development and validity evidence for the processes of change in Psychological Skills Training Questionnaire. Psychology of Sport and Exercise. 2015; 16: 79-87. doi: 10.1016/j.psychsport.2014.09.009. 